\title{
VIM-1 carbapenemase-producing Escherichia coli isolated from retail seafood, Germany 2016
}

Nicole Roschanski1, Sebastian Guenther ${ }^{1}$, Thi Thu Tra Vu², Jennie Fischer ${ }^{3}$, Torsten Semmler ${ }^{4}$, Stephan Huehn ${ }^{2,5}$, Thomas Alter ${ }^{2}$, Uwe Roesler ${ }^{1}$

1. Freie Universitaet Berlin, Institute for Animal Hygiene and Environmental Health, Berlin, Germany

2. Freie Universitaet Berlin, Institute of Food Safety and Food Hygiene, Berlin, Germany

3. Federal Institute for Risk Assessment, Department Biological Safety, Berlin, Germany

4. Robert Koch Institute, Berlin, Germany

5. Beuth University of Applied Sciences, Life Science and Technology, Berlin, Germany

Correspondence: Nicole Roschanski (nicole.roschanski@fu-berlin.de)

Carbapenems belong to the group of last resort antibiotics in human medicine. Therefore, the emergence of growing numbers of carbapenemase-producing bacteria in food-producing animals or the environment is worrying and an important concern for the public health sector. In the present study, a set of 45 Enterobacteriaceae isolated from German retail seafood (clams and shrimps), sampled in 2016, were investigated by real-time PCR for the presence of carbapenemase-producing bacteria. One Escherichia coli (ST10), isolated from a Venus clam (Ruditapes philippinarum) harvested in the Mediterranean Sea (Italy), contained the carbapenemase gene bla $a_{\mathrm{VIM-1}}$ as part of the variable region of a class I integron. Wholegenome sequencing indicated that the integron was embedded in a Tn3-like transposon that also contained the fluoroquinolone resistance gene $q n r S_{1}$. Additional resistance genes such as the extended-spectrum betalactamase bla $a_{\mathrm{SHV}-12}$ and the AmpC gene bla $a_{\mathrm{ACC}-1}$ were also present in this isolate. Except $b l a_{\mathrm{ACC}-1}$, all resistance genes were located on an IncY plasmid. These results confirm previous observations that carbapenemase-producing bacteria have reached the food chain and are of increasing concern for public health.

\section{Introduction}

In human medicine, carbapenems are one of the last treatment options for serious infections caused by multidrug-resistant Gram-negative bacteria [1]. Therefore, the increasing number of reports describing carbapenemase-producing Enterobacteriaceae are worrying. In the past six years, it has become obvious that the occurrence of carbapenemase-producing bacteria is no longer limited to clinical settings. Increasing numbers of carbapenemase-producing bacteria have been isolated from the environment, wild birds and companion and food-producing animals all over the world [2]. Although the use of carbapenems is prohibited in food-producing animals and restricted for pets in most European countries, these findings illustrate the continuous spread of these highly resistant bacteria accompanied by emerging public health problems. In 2011, the first VIM-1 producing Salmonella Infantis and Escherichia coli were isolated in German fattening farms for pigs and chickens $[3,4]$.

European Union legislation implemented monitoring of carbapenem-resistance in Salmonella and E. coli in food-producing animals (chickens, turkeys, pigs and cattle) and the derived meat samples [5]. Similarly structured resistance surveillance programmes, targeting bacterial isolates derived from food-producing animals and retail meat, are in place globally [6]. Vegetables, fruits or seafood are frequently consumed raw and thus may become a source of antimicrobial resistant bacteria, including carbapenemase-producing microorganisms [6-8]. Microbial contamination of the environment with faecal bacteria is an important route of transmission. For example, bacteria in river water may move on to seas and oceans [9]. Therefore, seafood harvested from contaminated regions serves as a vehicle for the transmission of these bacteria [10]. On the other hand, aquaculture is a fast-growing food production sector [11].

To prevent bacterial infections in the farmed fish, intensive aquaculture is often accompanied by increased use of a wide range of chemotherapeutic agents, in particular antibiotics [11]. This situation supports the occurrence and spread of antibiotic-resistant bacteria in seafood products. Fish and seafood play an important role on the food market. The global food fish supply has increased at an average annual rate of $3.2 \%$ (1961-2013); fish consumption per capita increased 
Comparison of the bla $\mathrm{VIM}-1_{1}$-containing transposon region of the plasmids pOW16C2 isolated from Klebsiella pneumoniae derived from river water sampled in Switzerland and pE-124-4 isolated from Escherichia coli derived from retail seafood, Germany, 2016

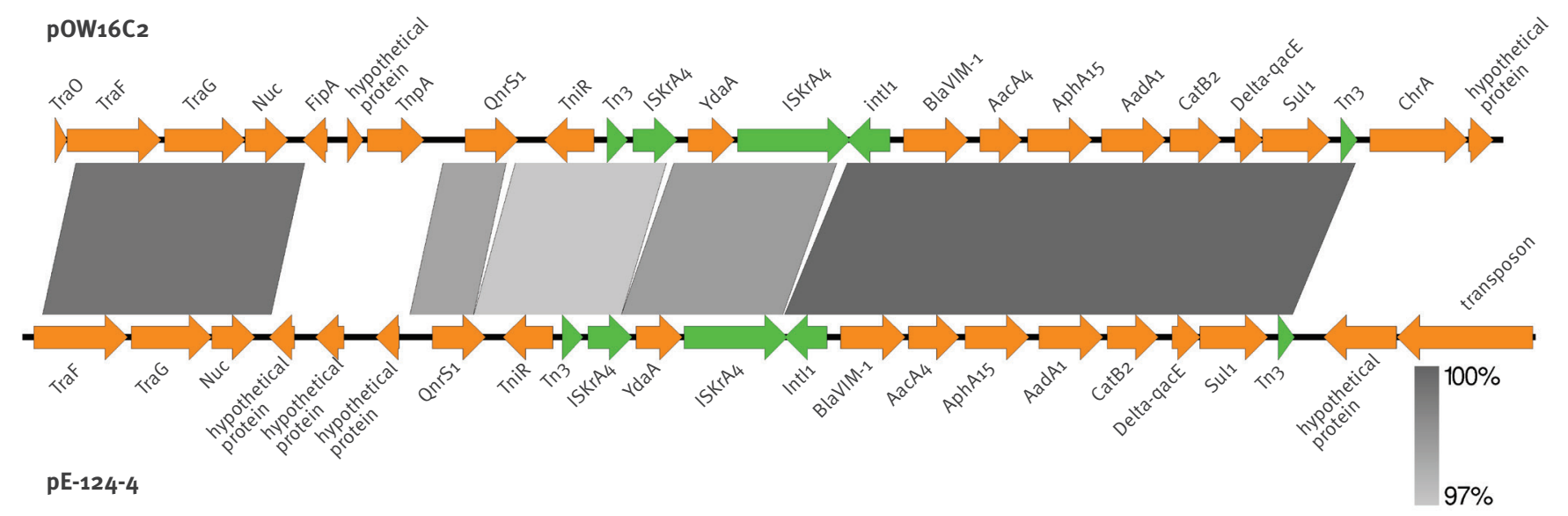

GenBank accession number of the blaVIM-1 containing transposon region of pE-124-4: MG182343.*

similarly from an average of $9.9 \mathrm{~kg} /$ year in the $1960 \mathrm{~s}$ to $20.1 \mathrm{~kg} /$ year in 2014 [12]. Several publications report the presence of antibiotic-resistant bacteria in seafood [10,13-15]. The first carbapenemase-producing bacteria derived from seafood were described in 2014, when a bla ${ }_{\text {VIM-2 }}$ containing Pseudomonas fluorescens was isolated from a squid from South Korea [8]. One year later, a study described the occurrence of bla $a_{\mathrm{OXA}-48}$-producing bacteria in $3.3 \%$ of the investigated seafood samples (squid, sea squirt, clams and seafood medley) from China and Korea [6].

In the present study, seafood samples from retail markets in Berlin, Germany, were investigated for the presence of carbapenemase-producing Enterobacteriaceae.

\section{Methods}

\section{Detection of carbapenemase-producing Enterobacteriaceae}

A set of 160 seafood samples ( 80 shrimp, 49 blue mussels, 15 Venus clams, 11 razor shells and five cockles) derived from 12 independent sellers in Berlin was sampled between December 2015 and August 2016 and initially investigated for the presence of ESBL/ AmpC-producing bacteria (data not shown). In that set, 45 Enterobacteriaceae were isolated: Klebsiella pneumoniae $(n=13)$ and E. coli $(n=12)$ were the predominant species, followed by Enterobacter cloacae $(n=6)$, Citrobacter freundii $(n=5)$, Hafnia alvei $(\mathrm{n}=3)$, Pantoea septica $(\mathrm{n}=1)$, Enterobacter aerogenes $(n=1)$, Morganella morganii $(n=1)$, Citrobacter braakii $(n=1)$, Enterobacter asburiae $(n=1)$ and Leclercia adecarboxylata $(\mathrm{n}=1)$. In the present study, the 45 DNA samples were additionally screened for the presence of the carbapenemase encoding genes $b l a_{\mathrm{VIM}}$, $b l a_{\mathrm{KPC}}$, $b l a_{\mathrm{NDM}}, b / a_{\mathrm{OXA}-48}$ and $b l a_{\mathrm{GES}}$ by real-time PCR [16]. The detected $b a_{\mathrm{VIM}-1}$ gene was amplified and sequenced [17].

Further characterisation of a $b l a_{\mathrm{VIM}-1}-$ containing Escherichia coli isolate

The phylogenetic group was determined by PCR [18], the class I integron was amplified and the purified amplification products were sequenced as described previously [4]. Plasmid DNA was isolated using the NucleoBond Xtra Midi kit (Macherey-Nagel, Dueren, Germany) and the bla VIM-1 $^{-}$containing plasmid was transferred into electrocompetent $E$. coliNEB10-beta (New England Biolabs, Frankfurt a.M., Germany). The incompatibility (Inc-) group of the plasmid was determined by using the PCR-based replicon typing (PBRT) kit (Diatheva, Fano, Italy). The size of the bla $a_{\text {vIm. }}$ - containing plasmid was estimated by S1 nuclease pulsed-field gel electrophoresis (PFGE) [19] using the following running conditions: $1-25 \mathrm{~s}, 17 \mathrm{~h}, 6 \mathrm{~V} / \mathrm{cm}, 120$ $V$. In addition, genomic DNA from the $E$. coli wild-type strain $\mathrm{E}-124-4$ as well as the transformant $\mathrm{T}_{\mathrm{E}-124-4}$ and the recipient strain NEB10-beta was isolated from overnight cultures of the selected isolates using the PureLink Genomic DNA Mini Kit (Invitrogen, Waltham, United States (US)). Sequencing libraries were generated with the Nextera XT DNA Sample Preparation Kit and paired-end sequencing was performed on the Illumina MiSeq benchtop using the MiSeq Reagent v3 600-cycle Kit $(2 \times 300 \mathrm{bp})$ (Illumina, San Diego, US). The raw data were assembled de novo using CLC Genomics workbench v.9.o (http://www.clcbio.com/). Resistance genes, plasmid incompatibility groups as well as multilocus sequence types were identified using the Web-tools ResFinder 2.1 [20], PlasmidFinder 1.3 [21], VirulenceFinder 1.5 [22] and MLST 1.8 [23], using the scheme by Wirth et al. [24]. Plasmid sequences were 
Whole genome sequence comparison of the Escherichia coli wild-type isolate (E-124-4) derived from retail seafood and its transformant $\left(\mathrm{T}_{\mathrm{E}-124-4)}\right.$, Germany, 2016

\begin{tabular}{|c|c|c|c|c|}
\hline Isolate & ST & Resistance genes & $\begin{array}{l}\text { Plasmid incompatibility } \\
\text { group }\end{array}$ & $\begin{array}{l}\text { Genes associated } \\
\text { with virulence }\end{array}$ \\
\hline E-124-4 & ST-10 & 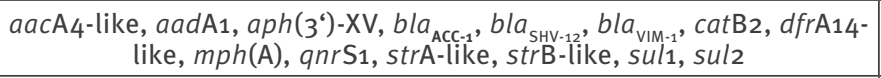 & IncY & gad \\
\hline $\mathrm{T}_{\mathrm{E}-124-4}$ & ST-1060 & $\begin{array}{l}\text { aacA4-like, aadA1, aph(3')-XV, bla }{ }_{\mathrm{SHV}-12}, \text { bla } a_{\mathrm{VIM}-1}, \text { catB2, dfrA14- } \\
\text { like, } \operatorname{mph}(\mathrm{A}), \text { anrS1, strA-like, strB-like, sul1, sul2 }\end{array}$ & IncY & gad, iss \\
\hline $\begin{array}{l}\text { NEB10- } \\
\text { beta }\end{array}$ & ST-1060 & none & none & gad, iss \\
\hline
\end{tabular}

ST: sequence type.

E-124-4 GenBank accession number: PDDPoooooooo.

For comparison, the recipient strain NEB10-beta is also included. Except bla ${ }_{\mathrm{AcC}-1}$ (bold letters), all of the detected resistance genes were transferred by electroporation.

extracted from the set of whole genome data by reductive sequence analysis of the transformant and the recipient strain. The resulting plasmid contigs where compared with available plasmid sequences using the Basic Local Alignment Search Tool (BLAST; National Center for Biotechnology Information; https://blast. ncbi.nlm.nih.gov/Blast.cgi?PAGE_TYPE=BlastSearch) and the software Geneious 7.1.2. Insertion sequence elements were detected by using the IS Finder (https:// www-is.biotoul.fr/blast.php).

Minimal inhibitory concentrations for a set of different antibiotics were investigated using the VITEK-2 compact system and the AST-card N248 (bioMérieux, Nuertingen, Germany). In addition, a disc diffusion assay described by the norm CLSI-Mo2-A11 [25] was performed using the following carbapenem discs: meropenem (MEM) $(10 \mu \mathrm{g})$, imipenem (IMI) (10 $\mu \mathrm{g})$ and ertapenem (ETP) $(10 \mu \mathrm{g})$ (bestbion, Cologne, Germany). The obtained data were interpreted following Clinical and Laboratory Standards Institute (CLSI) guidelines CLSI-M100-S24 [26].

\section{Results}

\section{Genotypic characterisation}

Among the 45 investigated Enterobacteriaceae, one $E$. coli isolate (E-124-4) was found to be positive for the carbapenemase gene bla $a_{\mathrm{VIM}-1}$. The isolate belonged to the phylogenetic group A, sequence type ST10, and was originally isolated from a Venus clam (Ruditapes philippinarum). Plasmid electroporation, replicon typing, S1 nuclease PFGE (data not shown) as well as whole genome sequence data (E-124-4: coverage $130 \times$, contigs $\mathrm{n}=157 ; \mathrm{T}_{\mathrm{E}-124-4}$ : coverage $100 \times$, contigs $\mathrm{n}=203$; NEB10-beta coverage $120 \times$, contigs: $n=142$ ) indicated that the carbapenemase gene was located on an IncY plasmid (pE-124-4) of ca $194 \mathrm{~kb}$. Sequence analyses showed that bla $a_{\text {VIM-1 }}$ was located within a class I integron (E-124-4 GenBank accession number: PDDPoooooooo). Besides the carbapenemase gene $b a_{\mathrm{VIM}-1}$, genes for the aminoglycoside 6'- $\mathrm{N}$-acetyltransferase aacA4, the aminoglycoside phosphotransferase aph(3')-XV, the aminoglycoside adenylyltransferase aadA1 as well as the chloramphenicol acetyltransferase catB2 were detected in the variable region of the integron (Figure).

In addition, the conserved region at the 3'- end contained the sulphonamide resistance gene sul1. Besides the class I integron, the investigated isolate harboured eight additional antibiotic resistance genes conferring resistance to different classes of antimicrobials (Table 1).

The S1-PFGE (data not shown) confirmed the presence of a single plasmid in $\mathrm{T}_{\mathrm{E}-124-4}$. A genome comparison of the wildtype as well as the transformant and the recipient strain showed that 13 of the 14 detected resistance genes were co-located on the bla $a_{\mathrm{VIM}-1}$-containing IncY plasmid. Only the AmpC gene bla ${ }_{\mathrm{ACC}-1}$ was not transferred to the recipient strain. The whole genome data indicated that this gene was located on the $E$. coli chromosome. At the 5'-end, the bla $a_{\mathrm{AcC}-1}$ was associated with the insertion sequence ISECP1 followed by the genes sgbE (2-ribulose-5-phosphate-4-epimerase), rhaR (transcriptional activator) and yic)2 (inner membrane symporter) and on the 3'-end, ISKpn7 was detected adjacent to the genes gdhA (glutamate dehydrogenase), ulaE (L-ribulose-5-phosphate-3-epimerase) and $\mathrm{sgbH}$ (3-keto-L-gluconate-6-phosphate-decarboxylase). Comparison of the extracted IncY plasmid sequences showed that the plasmid contained a mixture of different plasmid components and had low overall similarity with all published IncY plasmids carrying $b l a_{\mathrm{VIM}-1}$. It is noteworthy that the class I integron detected here was located within a Tnz-like transposon, similar to the one previously reported in a $K$. pneumoniae isolated from a river in Switzerland [27]. The region located proximal to the class I integron contained the qnrS1 gene, tniR encoding a resolvase/ integrase, the Tnz-like transposase, ISKrA4 as well as the putative transposon resolvase $y d a \mathrm{~A}$. However, at the distal end of the integron, only the Tnz-like transposase was located adjacent to the sul1 gene (Figure). 
Minimum inhibitory concentrations of the Escherichia coli wild-type isolate (E-124-4) derived from retail seafood and its transformant $\left(\mathrm{T}_{\mathrm{E}-124-4}\right)$, Germany 2016

\begin{tabular}{|l|l|l|l|l|l|l|l|l|l|l|l|l|l|l|l|l|l|}
\hline Isolate & Time of assessment & PIP & PIP-TAZ & CTX & CAZ & FEP & ATM & IMI & MEM & AMK & GE & TBM & CIP & TGC & FOS & COL & SXT \\
\hline E-124-4 & 11 August 2016 & $\geq 128$ & $\geq 128$ & 4 & $\geq 64$ & $\leq 1$ & 16 & $\leq 0.25$ & $\leq 0.25$ & $\leq 2$ & $\leq 1$ & 2 & $\leq 0.25$ & $\leq 0.5$ & $\leq 16$ & $\leq 0.5$ & $\geq 320$ \\
\hline E-124-4 & \multirow{2}{*}{ 21 September 2016} & $\geq 128$ & $\geq 128$ & $\geq 64$ & $\geq 64$ & 4 & $\geq 64$ & 8 & $\geq 16$ & 4 & 2 & 8 & $\leq 0.25$ & $\leq 0.5$ & $\leq 16$ & $\leq 0.5$ & $\geq 320$ \\
\cline { 1 - 30 } & & $\geq 128$ & $f$ & $\geq 64$ & $\geq 64$ & $\geq 64$ & $\geq 64$ & 8 & 8 & 8 & 2 & 8 & 0.5 & $\leq 0.5$ & $\leq 16$ & 2 & $\geq 320$ \\
\hline
\end{tabular}

AMK:amikacin; ATM: aztreonam; CAZ: ceftazidime; CIP: ciprofloxacin; COL: colistin; CTX: cefotaxime; f: failed run; FEP: cefepime;

FOS: fosfomycin; GE: gentamicin; IMI: imipenem; MEM: meropenem; PIP: piperacillin; PIP-TAZ: piperacillin/tazobactam; TBM: tobramycin;

TGC: tigecycline; SXT: trimethoprim/sulfamethoxazole.

Dark shading: resistant according to CLSI. Light shading: Intermediate according to CLSI.

Minimum inhibitory concentrations $[\mu \mathrm{g} / \mathrm{mL}$ ] determined by AST-card N248 (VITEK-2 compact system (bioMérieux, Nuertingen, Germany). The wild-type isolate (E-124-4) was investigated at two different time points (11 August 2016: after primary detection of the bla ${ }_{\text {VIM-1 }}$ gene; 21 September 2016: after some weeks of cultivation in vitro). $\mathrm{T}_{\mathrm{E}-124-4}$ : transformant (NEB10-beta containing the IncY plasmid).

\section{Phenotypic characterisation}

Besides the genetic background, we also investigated phenotypic resistances at two different time points: first, the minimal inhibitory concentration (MIC) for the wildtype isolate E-124-4 was determined immediately after the PCR-detection of the $b a_{\mathrm{VIM}-1}$ gene (11 August 2016). At this time point, no carbapenem resistance against IMI as well as MEM was detected using the VITEK-2 compact system (Table 2). Due to the fact that ETP was not included on the AST card N248 and the presence of the $b{ } a_{\mathrm{VIM}-1}$ gene was already proved by sequencing, the results were reassessed by disc diffusion including the three carbapenems IMI, MEM and ETP. Thereby the following zone diameters were obtained: IMI: $21 \mathrm{~mm}$; MEM: $24 \mathrm{~mm}$; ETP: $25 \mathrm{~mm}$. According to CLSI-M100-S24, these diameters indicated a carbapenem-sensitive phenotype. However, according to the European Food Safety Authority, the measured zone diameters of $24 \mathrm{~mm}$ for MEM and $25 \mathrm{~mm}$ for ETP were indicative of non-susceptibility to carbapenems [28]. A simultaneous cultivation in liquid medium containing either $2 \mu \mathrm{g} / \mathrm{mL}$ or $8 \mu \mathrm{g} / \mathrm{mL}$ meropenem indicated that the isolate was able to grow under selective conditions.

Following the completion of the other experiments such as plasmid preparation and transformation, the MIC determination was repeated on 21 September 2016 and showed that E-124-4 as well as its transformant $\mathrm{T}_{\mathrm{E}-124-4}$ had gained full carbapenem resistance (Table 2).

\section{Discussion}

Increasing numbers of antibiotic-resistant Enterobacteriaceae cause continuous problems in infection control and the global spread of carbapenemase-producing bacteria is especially worrisome [29]. In this study, we describe a bla $a_{\text {VIM-1 }}$-containing $E$. coli ( $\left.\mathrm{ST}_{10}\right)$ isolate derived from a Venus clam, harvested in the Mediterranean Sea (Italy) and purchased at a German retail market. This emphasises the importance of the food production chain in the global spread of antibiotic-resistant bacteria.
At the same time, it has to be considered that the detection of carbapenemase producers is complex and that a single screening method is not always sufficient for the detection of this kind of isolate [30]. The first MIC determination using the AST-card N248 (bioMérieux) immediately after arrival of the samples suggested a carbapenem-sensitive phenotype according to CLSIM100-S24. This was confirmed by a disc diffusion assay, as indicated by the CLSI guidelines. However, according to the European Food Safety Authority, the measured zone diameters for MEM as well as ETP were indicative of non-susceptibility to carbapenems [28]. When the wild-type isolate and its transformant were retested by MIC assay several weeks later, both of them exhibited a full resistant phenotype. The identification of bacterial isolates harbouring carbapenemase genes has frequently been described as challenging. Because the presence of a carbapenemase (e.g. KPC, VIM-1) not always leads to a high-level carbapenem resistance in laboratory testing, the isolates are often wrongly assessed as carbapenem-susceptible. Therefore, in human medicine, carbapenemase- producing bacteria are often detected only in case of therapy failure [31-34]. In 2015, Adams-Sapper et al. described that in the case of KPC-producing K. pneumoniae, a single exposure to a carbapenem was enough to generate subpopulations of high-level resistant bacteria [35]. Therefore, the real occurrence of carbapenem-resistant bacteria in food samples as well as food-producing animals or the environment can easily be underestimated.

Moreover, it is important to mention the limitations of the present study. The screening was based on isolates initially selected on MacConkey agar plates containing $1 \mu \mathrm{g} / \mathrm{mL}$ cefotaxime. Therefore, isolates possessing a carbapenemase of the OXA family (e.g. OXA-48), without a coexisting resistance mechanism conferring resistance to oxyimino-cephalosporins such as extended spectrum- or AmpC-type beta-lactamases, may not have been detected. As the occurrence of carbapenemase-producing bacteria in effluent and sewage water, hospital sewage as well as river and coastal water samples has been described frequently, 
the pollution of seafood was merely a matter of time [36-40].

In addition, the detected $E$. coli sequence type ST10 is widespread among clinical as well as animal samples (e.g. seagulls) and wastewater [41-45]. In 2014 and 2015, a Canadian research group described the occurrence of bla $a_{\mathrm{VIM}-2}$ - and bla ${ }_{\mathrm{OXA}-48}$-producing bacteria in seafood from China and Korea [6,8]. This study was followed by findings such as OXA-23-producing Acinetobacter baumanii, isolated from the fish Pagellus acarne harvested in the Mediterranean Sea [46], carbapenem-resistant Enterobacter derived from imported retail seafood in Canada [47] and VCC-1, a newly described Ambler class A carbapenemase from Vibrio cholerae isolated from imported retail shrimp sold in Canada [48]. These findings clearly demonstrate that carbapenemase-producing Enterobacteriaceae are present in the oceans and may enter the human food chain along this pathway. Our detection of a carbapenemase-producing $E$. coli isolated from a Venus clam, bought at a German retail market, supports this theory.

This study showed that the $E$. coli isolate derived from a Venus clam possessed a mixture of different resistance genes and parts of resistance plasmids. Interestingly, a similar Tn3-like transposon, which harboured a class I integron consisting of the bla $a_{\mathrm{VIM}-1}$ gene accompanied by accA4, aph (3')-XV, aadA1 and catB2 in its variable region, was recently described in a $K$. pneumoniae isolated from a river in Switzerland [27]. However, the plasmid carrying this integron was different from the plasmid in our isolate. These findings underline the importance of mobile genetic elements (plasmids or transposons) for the spread of carbapenemase-producing bacteria and demonstrate that this is an important risk factor that deserves special attention.

Because the clam was fished in Italy, we compared E-124-4 with previously published $b / a_{\mathrm{VIM}-1}$ isolates reported from that country: the association of bla $a_{\mathrm{VIM}-1}$ and $b a_{\mathrm{SHV}-12}$ on the same plasmid has already been described for Enterobacteriaceae derived from an Italian tertiary-care hospital [49], however, the detected plasmid replicon type was IncN, while the plasmid investigated here belonged to the IncY group. In addition, a similar class 1 integron was discovered in Achromobacter xylosoxydans isolated from a urine sample of an inpatient at the University Hospital of Verona, Italy [50]. Similarly to E-124-4, it contained bla $a_{\mathrm{VIM}-1}$ accompanied by accA4, aph (3')$X V$ and aad $\mathrm{A}_{1}$ in its variable region. However, no cat $\mathrm{B}_{2}$ was detected in that Achromobacter isolate. Despite the integron similarity, no further consistencies among the two plasmids have been detected. While the plasmid pAX 2220 was $30 \mathrm{~kb}$ in size and did not contain an additional bla $a_{\mathrm{SHV}-12}, \mathrm{pE}-124-4$ was much larger, ca194 $\mathrm{kb}$.

Moreover, it has to be taken into account that Venus clams are also served as a raw appetiser and that seafood is preferred raw in some regions, providing ideal conditions for the transmission and spread of the carbapenemase-producing bacteria or a transfer of the respective plasmids.

This situation emphasises the importance of further monitoring programmes as well as the need for the seafood samples to be included into the national surveillance programmes. Similarly, comprehensive intervention strategies focussing on the prudent use of antibiotics as well as the prevention of an environmental spread of the resistant bacteria are crucial in human as well as veterinary medicine.

\section{*Author's correction}

The GenBank accession number of the blaVIM-1 containing transposon region of $\mathrm{pE}-124-4$ was originally published as $M G 18234$. This number was corrected to MG182343 on 9 November 2017.

\section{Acknowledgements}

We would like to thank our technician Maja Thieck for committed assistance in the laboratory. Special thanks to Beatriz Guerra for her advice and review of the manuscript before submission. Olga Makarova and Jayaseelan Murugaiyan are gratefully acknowledged for critical reading of the manuscript.

\section{Conflict of interest}

None declared.

\section{Authors' contributions}

N.R. designed the experiments, performed parts of the laboratory work, evaluated the data and wrote the manuscript. S.G. performed the MIC determination and contributed to the manuscript writing. S.G. and T.S. performed WGS assemblies and analysed the WGS-data. T.T.T.V. and S.H. collected the seafood samples. T.T.T.V. isolated the Enterobacteriaceae and prepared the respective DNAs. S.H. and T.A. designed the initial samplings at the retail markets. J.F. generated sequencing libraries and performed the whole genome sequencing. T.A. and U.R. contributed to the initial study design.

\section{References}

1. World Health Organization (WHO). Critically important antimicrobials for human medicine. 3rd revision 2011. Geneva: WHO; 2012. Available from: http://apps.who.int/iris/ bitstream/10665/77376/1/9789241504485_eng.pdf

2. Woodford N, Wareham DW, Guerra B, Teale C. Carbapenemaseproducing Enterobacteriaceae and non-Enterobacteriaceae from animals and the environment: an emerging public health risk of our own making? J Antimicrob Chemother. 2014;69(2):287-91. https://doi.org/10.1093/jac/dkt392 PMID: 24092657

3. Fischer J, Rodríguez I, Schmoger S, Friese A, Roesler $\mathrm{U}$, Helmuth R, et al. Escherichia coli producing VIM1 carbapenemase isolated on a pig farm. J Antimicrob Chemother. 2012;67(7):1793-5. https://doi.org/10.1093/jac/ dks108 PMID: 22454489

4. Fischer J, Rodríguez I, Schmoger S, Friese A, Roesler U, Helmuth R, et al. Salmonella enterica subsp. enterica producing VIM-1 carbapenemase isolated from livestock farms. 
J Antimicrob Chemother. 2013;68(2):478-80. https://doi. org/10.1093/jac/dks393 PMID: 23034713

5. European Commission. Commission implementing decision $2013 / 652 / E U$ on the monitoring and reporting of antimicrobial resistance in zoonotic and commensal bacteria. Official Journal of the European Union. Luxembourg: Publications Office of the European Union. 14.11.2013; L303. Available from: http://eurlex.europa.eu/legal-content/EN/TXT/PDF/?uri=0J:L:2013:303:F ULL\&from $=E N$

6. Morrison BJ, Rubin JE. Carbapenemase producing bacteria in the food supply escaping detection. PLoS One. 2015;10(5):e0126717. https://doi.org/10.1371/journal. pone.0126717 PMID: 25966303

7. Zurfluh K, Poirel L, Nordmann P, Klumpp J, Stephan R. First detection of Klebsiella variicola producing OXA-181 carbapenemase in fresh vegetable imported from Asia to Switzerland. Antimicrob Resist Infect Control. 2015;4(1):38. https://doi.org/10.1186/s13756-015-0080-5 PMID: 26448862

8. Rubin JE, Ekanayake S, Fernando C. Carbapenemase-producing organism in food, 2014. Emerg Infect Dis. 2014;20(7):1264-5. https://doi.org/10.3201/eid2007.140534 PMID: 24960459

9. Páll E, Niculae M, Kiss T, Şandru CD, Spînu M. Human impact on the microbiological water quality of the rivers. J Med Microbiol. 2013;62(Pt 11):1635-40. https://doi.org/10.1099/ jmm.0.055749-0 PMID: 23813274

10. Kumaran S, Deivasigamani B, Alagappan K, Sakthivel M, Karthikeyan R. Antibiotic resistant Esherichia coli strains from seafood and its susceptibility to seaweed extracts. Asian Pac J Trop Med. 2010;3(12):977-81. https://doi.org/10.1016/ S1995-7645(11)60013-8

11. Rogers $C$, Basurco B, editors. The use of veterinary drugs and vaccines in Mediterranean aquaculture. Zaragoza: Centre International de Hautes Etudes Agronomiques Méditerranéennes (CIHEAM); 2009. 223 p. Available from: http://om.ciheam.org/option.php?IDOM=387

12. Food and Agriculture Organization of the United Nations (FAO). The state of world fisheries and aquaculture. Contributing to food security and nutrition for all. Rome: FAO; 2016. Available from: http://www.fao.org/3/a-i5555e.pdf

13. Rahiman KMM, Hatha AAM, Selvam ADG, Thomas AP. Relative prevalence of antibiotic resistance among heterotrophic bacteria from natural and culture environments of freshwater rawn, Macrobrachium Rosenbergii. J World Aquacult Soc. 2016;47(4):470-80. https://doi.org/10.1111/jwas.12287

14. Boss R, Overesch G, Baumgartner A. Antimicrobial resistance of Escherichia coli, Enterococci, Pseudomonas aeruginosa, and Staphylococcus aureus from raw fish and seafood imported into Switzerland. J Food Prot. 2016;79(7):1240-6. https://doi. org/10.4315/0362-028X.JFP-15-463 PMID: 27357045

15. Sperling L, Alter T, Huehn S. Prevalence and antimicrobial resistance of Vibrio spp. in retail and farm shrimps in Ecuador. J Food Prot. 2015;78(11):2089-92. https://doi. org/10.4315/0362-028X.JFP-15-160 PMID: 26555534

16. Roschanski N, Friese A, von Salviati-Claudius C, Hering J, Kaesbohrer A, Kreienbrock L, et al. Prevalence of carbapenemase producing Enterobacteriaceae isolated from German pig-fattening farms during the years 2011-2013. Vet Microbiol. 2017;200:124-9. https://doi.org/10.1016/j. vetmic.2015.11.030 PMID: 26654218

17. Poirel L, Naas T, Nicolas D, Collet L, Bellais S, Cavallo JD, et al. Characterization of VIM-2, a carbapenem-hydrolyzing metallobeta-lactamase and its plasmid- and integron-borne gene from a Pseudomonas aeruginosa clinical isolate in France. Antimicrob Agents Chemother. 2000;44(4):891-7. https://doi. org/10.1128/AAC.44.4.891-897.2000 PMID: 10722487

18. Clermont O, Christenson JK, Denamur E, Gordon DM. The Clermont Escherichia coli phylo-typing method revisited: improvement of specificity and detection of new phylogroups. Environ Microbiol Rep. 2013;5(1):58-65. https://doi. org/10.1111/1758-2229.12019 PMID: 23757131

19. Guerra B, Junker E, Miko A, Helmuth R, Mendoza MC Characterization and localization of drug resistance determinants in multidrug-resistant, integron-carrying Salmonella enterica serotype Typhimurium strains. Microb Drug Resist. 2004;10(2):83-91. https://doi. org/10.1089/1076629041310136 PMID: 15256022

20. Zankari E, Hasman H, Cosentino S, Vestergaard M, Rasmussen $\mathrm{S}$, Lund $\mathrm{O}$, et al. Identification of acquired antimicrobial resistance genes. J Antimicrob Chemother. 2012;67(11):2640-4. https://doi.org/10.1093/jac/dks261 PMID: 22782487

21. Carattoli A, Zankari E, García-Fernández A, Voldby Larsen M, Lund $\mathrm{O}$, Villa L, et al. In silico detection and typing of plasmids using PlasmidFinder and plasmid multilocus sequence typing. Antimicrob Agents Chemother. 2014;58(7):3895-903. https:// doi.org/10.1128/AAC.02412-14 PMID: 24777092
22. Joensen KG, Scheutz F, Lund O, Hasman H, Kaas RS, Nielsen $E M$, et al. Real-time whole-genome sequencing for routine typing, surveillance, and outbreak detection of verotoxigenic Escherichia coli. J Clin Microbiol. 2014;52(5):1501-10. https:// doi.org/10.1128/JCM.03617-13 PMID: 24574290

23. Larsen MV, Cosentino S, Rasmussen S, Friis C, Hasman H, Marvig RL, et al. Multilocus sequence typing of total-genomesequenced bacteria. J Clin Microbiol. 2012;50(4):1355-61. https://doi.org/10.1128/JCM.06094-11 PMID: 22238442

24. Wirth T, Falush D, Lan R, Colles F, Mensa P, Wieler LH, et al. Sex and virulence in Escherichia coli: an evolutionary perspective. Mol Microbiol. 2006;60(5):1136-51. https://doi.org/10.1111/ j.1365-2958.2006.05172.x PMID: 16689791

25. Clinical and Laboratory Standards Institute (CLSI). Performance standards for antimicrobial disk susceptibility tests. Approved standard-eleventh edition. Mo2-A11. 32. Wayne, PA: CLSI; 2012.

26. Clinical and Laboratory Standards Institute (CLSI). Performance standards for antimicrobial susceptibility testing. Twenty-Fourth Informational Supplement. M100-S24. ISBN:1562388975. Wayne, PA: CLSI; 2014.

27. Zurfluh K, Power KA, Klumpp J, Wang J, Fanning S, Stephan R. A novel Tn3-like composite transposon harboring blaVIM-1 in Klebsiella pneumoniae spp. pneumoniae isolated from river water. Microb Drug Resist. 2015;21(1):43-9. https://doi. org/10.1089/mdr.2014.0055 PMID: 25098892

28. European Food Safety Authority (EFSA). Scientific opinion on carbapenem resistance in food animal ecosystems. EFSA J. 2013;11(12):3501. Available from: https://www.efsa.europa. eu/en/efsajournal/pub/3501 https://doi.org/10.2903/j. efsa.2013.3501

29. Nordmann P, Naas T, Poirel L. Global spread of carbapenemase-producing Enterobacteriaceae. Emerg Infect Dis. 2011;17(10):1791-8. https://doi.org/10.3201/ eid1710.110655 PMID: 22000347

30. Lutgring JD, Limbago BM. The problem of carbapenemaseproducing-carbapenem-resistant-Enterobacteriaceae detection. J Clin Microbiol. 2016;54(3):529-34. https://doi.org/10.1128/ JCM.02771-15 PMID: 26739152

31. Hirsch EB, Tam VH. Detection and treatment options for Klebsiella pneumoniae carbapenemases (KPCs): an emerging cause of multidrug-resistant infection. J Antimicrob Chemother. 2010;65(6):1119-25. https://doi.org/10.1093/jac/dkq108 PMID: 20378670

32. Falcone M, Mezzatesta ML, Perilli M, Forcella C, Giordano A, Cafiso V, et al. Infections with VIM-1 metallo-beta-lactamaseproducing enterobacter cloacae and their correlation with clinical outcome. J Clin Microbiol. 2009;47(11):3514-9. https:// doi.org/10.1128/JCM.01193-09 PMID: 19741074

33. Falcone M, Perilli M, Mezzatesta ML, Mancini C, Amicosante G, Stefani S, et al. Prolonged bacteraemia caused by VIM-1 metallo-beta-lactamase-producing Proteus mirabilis: first report from Italy. Clin Microbiol Infect. 2010;16(2):179-81. https://doi.org/10.1111/j.1469-0691.2009.02781.x PMID: 19624511

34. Weisenberg SA, Morgan DJ, Espinal-Witter R, Larone DH. Clinical outcomes of patients with Klebsiella pneumoniae carbapenemase-producing K. pneumoniae after treatment with imipenem or meropenem. Diagn Microbiol Infect Dis. 2009;64(2):233-5. https://doi.org/10.1016/j. diagmicrobio.2009.02.004 PMID: 19345034

35. Adams-Sapper S, Nolen S, Donzelli GF, Lal M, Chen K, Justo da Silva LH, et al. Rapid induction of high-level carbapenem resistance in heteroresistant KPC-producing Klebsiella pneumoniae. Antimicrob Agents Chemother. 2015;59(6):3281-9 https://doi.org/10.1128/AAC.05100-14 PMID: 25801565

36. Perilli M, Bottoni C, Pontieri E, Segatore B, Celenza G, Setacci D, et al. Emergence of blaKPC-3-Tn4401a in Klebsiella pneumoniae $\mathrm{ST}_{512}$ in the municipal wastewater treatment plant and in the university hospital of a town in central Italy. J Glob Antimicrob Resist. 2013;1(4):217-20. https://doi.org/10.1016/j. jgar.2013.07.002 PMID: 27873616

37. Poirel L, Barbosa-Vasconcelos A, Simões RR, Da Costa PM, Liu W, Nordmann P. Environmental KPC-producing Escherichia coli isolates in Portugal. Antimicrob Agents Chemother. 2012;56(3):1662-3. https://doi.org/10.1128/AAC.05850-11 PMID: 22203588

38. Kittinger C, Lipp M, Folli B, Kirschner A, Baumert R, Galler $\mathrm{H}$, et al. Enterobacteriaceae isolated from the river Danube: antibiotic resistances, with a focus on the presence of ESBL and carbapenemases. PLoS One. 2016;11(11):e0165820. https://doi.org/10.1371/journal.pone.0165820 PMID: 27812159

39. Zurfluh K, Hächler H, Nüesch-Inderbinen M, Stephan R. Characteristics of extended-spectrum $\beta$-lactamase- and carbapenemase-producing Enterobacteriaceae Isolates from rivers and lakes in Switzerland. Appl Environ Microbiol. 
2013;79(9):3021-6. https://doi.org/10.1128/AEM.00054-13 PMID: 23455339

40. Montezzi LF, Campana EH, Corrêa LL, Justo LH, Paschoal RP, da Silva IL, et al. Occurrence of carbapenemase-producing bacteria in coastal recreational waters. Int J Antimicrob Agents. 2015;45(2):174-7. https://doi.org/10.1016/j. ijantimicag.2014.10.016 PMID: 25499185

41. Oteo J, Diestra K, Juan C, Bautista V, Novais A, PérezVázquez M, et al. Extended-spectrum beta-lactamaseproducing Escherichia coli in Spain belong to a large variety of multilocus sequence typing types, including ST10 complex/A, ST23 complex/A and ST131/B2. Int J Antimicrob Agents. 2009;34(2):173-6. https://doi.org/10.1016/j. ijantimicag.2009.03.006 PMID: 19464856

42. Aibinu I, Odugbemi T, Koenig W, Ghebremedhin B. Sequence type ST131 and ST10 complex (ST617) predominant among CTX-M-15-producing Escherichia coli isolates from Nigeria. Clin Microbiol Infect. 2012;18(3):E49-51. https://doi.org/10.1111/ j.1469-0691.2011.03730.x PMID: 22192452

43. Blaak H, van Hoek AH, Hamidjaja RA, van der Plaats RQ, Kerkhof-de Heer L, de Roda Husman AM, et al. Distribution, numbers, and diversity of ESBL-producing $E$. coli in the poultry farm environment. PLoS One. 2015;10(8):e0135402. https:// doi.org/10.1371/journal.pone.0135402 PMID: 26270644

44. Simões RR, Poirel L, Da Costa PM, Nordmann P. Seagulls and beaches as reservoirs for multidrug-resistant Escherichia coli. Emerg Infect Dis. 2010;16(1):110-2. https://doi.org/10.3201/ eid1601.090896 PMID: 20031053

45. Varela AR, Macedo GN, Nunes OC, Manaia CM. Genetic characterization of fluoroquinolone resistant Escherichia coli from urban streams and municipal and hospital effluents. FEMS Microbiol Ecol. 2015;91(5):91. https://doi.org/10.1093/ femsec/fivo15 PMID: 25764463

46. Brahmi S, Touati $A$, Cadière $A$, Djahmi N, Pantel $A$, Sotto $A$, et al. First description of two sequence type 2 Acinetobacter baumannii isolates carrying OXA-23 carbapenemase in Pagellus acarne fished from the Mediterranean Sea near Bejaia, Algeria. Antimicrob Agents Chemother. 2016;60(4):2513-5. https://doi.org/10.1128/AAC.02384-15 PMID: 26787693

47. Janecko N, Martz SL, Avery BP, Daignault D, Desruisseau A, Boyd D, et al. Carbapenem-resistant Enterobacter spp. in retail seafood imported from Southeast Asia to Canada. Emerg Infect Dis. 2016;22(9):1675-7. https://doi.org/10.3201/ eid2209.160305 PMID: 27533255

48. Mangat CS, Boyd D, Janecko N, Martz SL, Desruisseau A, Carpenter M, et al. Characterization of VCC-1, a novel Ambler class A carbapenemase from Vibrio cholerae isolated from imported retail shrimp sold in Canada. Antimicrob Agents Chemother. 2016;6o(3):1819-25. https://doi.org/10.1128/ AAC.02812-15 PMID: 26824956

49. Aschbacher R, Pagani L, Doumith M, Pike R, Woodford $\mathrm{N}$, Spoladore G, et al. Metallo- $\beta$-lactamases among Enterobacteriaceae from routine samples in an Italian tertiarycare hospital and long-term care facilities during 2008. Clin Microbiol Infect. 2011;17(2):181-9. https://doi.org/10.1111/ j.1469-0691.2010.03225.x PMID: 20345467

50. Riccio ML, Pallecchi L, Fontana R, Rossolini GM. In7o of plasmid $\mathrm{pAX} 22$, a bla(VIM-1)-containing integron carrying a new aminoglycoside phosphotransferase gene cassette. Antimicrob Agents Chemother. 2001;45(4):1249-53. https:// doi.org/10.1128/AAC.45.4.1249-1253.2001 PMID: 11257042

\section{License and copyright}

This is an open-access article distributed under the terms of the Creative Commons Attribution (CC BY 4.0) Licence. You may share and adapt the material, but must give appropriate credit to the source, provide a link to the licence, and indicate if changes were made.

This article is copyright of the authors, 2017. 